\title{
Measurement of Friction in Cold Upsetting with Mist Lubrication*
}

\author{
Ryo Matsumoto and Kozo Osakada \\ Graduate School of Engineering Science, Osaka University, Toyonaka 560-8531, Japan
}

The coefficient of friction during upsetting under semi-dry conditions is measured using the ring compression test. A small amount of mist lubricant is sprayed onto the mirror surfaces of cemented tungsten carbide (WC) tools, and pure aluminium specimens are compressed by the tools. It is found that spraying a small amount of lubricant $\left(0.5 \mathrm{~g} / \mathrm{m}^{2}\right)$ reduces the friction effectively. The roughness of the workpieces after compression increases as the amount of the lubricant increases to $R_{a}=0.20-1.0 \mu \mathrm{m}$ which is in the same order as the lubricant film thickness. Mist lubrication results in very small dots of lubricant particles sticking to the tool surface, and the lubrication mechanism of mist lubricant is discussed.

(Received September 24, 2003; Accepted June 10, 2004)

Keywords: friction, upsetting, forging, minimal quantity lubricants (MQL), semi-dry condition, ring compression test

\section{Introduction}

Since metal forming induces high friction and heat generation between the tools and the workpiece, lubrication is a critically important factor in reducing forming pressure and avoiding seizure in many forming processes. However, many kinds of lubricants are now considered to be harmful to the environment, and the development of a dry metal forming process without lubrication, a semi-dry metal forming process that involves spraying a very small amount of lubricants and/or non-polluting lubricants is desired. ${ }^{1-6)}$ If dry metal forming is realized, its influence on the environment and the cost of production could be reduced markedly. ${ }^{7)}$

Dry metal cutting without lubrication has already become possible through the recent development of coating methods for cutting tools, for example, chemical vapor deposition (CVD) and physical vapor deposition (PVD) processes. ${ }^{8,9)}$ As well as dry metal cutting, the MQL (minimal quantity lubricants) process for metal cutting has been realized. While more than $100 \mathrm{~mL} / \mathrm{h}$ of lubricant is used in conventional metal cutting, less than $10 \mathrm{~mL} / \mathrm{h}$ of mist lubricant is sprayed in the MQL process on a workpiece. ${ }^{10,11)}$

In this study, the coefficient of friction under semi-dry conditions is measured using the ring compression test in order to realize dry and semi-dry metal forming processes. A small amount of mist lubricant (less than $3.0 \mathrm{~g} / \mathrm{m}^{2}$ ) is sprayed onto the surfaces of the compression tools using a mist spraying system for metal cutting. The surface profiles of the aluminium billet after upsetting is measured, and the behaviour of the trapped mist lubricant during upsetting is discussed.

\section{Ring Compression Test}

The coefficient of friction during forging with slight lubrication is measured using the ring compression test. ${ }^{12)}$ In this test, a ring specimen is compressed between the flat parallel tools and the coefficient of friction is determined on the basis of the change in the inner diameter of the ring. Since this method does not require the determination of the load, it

*This Paper was Originally Published in Japanese in Journal of the Japan Society for Technology of Plasticity 44-508 (2003) 535-539. has been frequently used for estimating friction during forging without large expansion of a billet surface.

In this study, initial ring specimens having a ratio of outer diameter: inner diameter:height $=3: 1: 1$ are used. This shape is chosen because it provides a good sensitivity to friction at high friction. ${ }^{7)}$ The tested material is pure aluminium, A1050 (annealed) and the roughness of the initial ring specimen is $0.30-0.50 \mu \mathrm{m}$. The tool has a disc shape with a diameter of $60 \mathrm{~mm}$ and a thickness of $8 \mathrm{~mm}$. The base material of the tool is a cemented tungsten carbide (WC: $85 \%$ and Co: $15 \%$ ) and the tool surface is polished to a mirror finish $\left(R_{a}=0.02 \mu \mathrm{m}\right)$.

The experiments are conducted on a $0.6 \mathrm{MN}$ (60 tonf) mechanical press with an average compressing speed of $150 \mathrm{~mm} / \mathrm{s}$ at room temperature and $200^{\circ} \mathrm{C}$. The ring specimens are compressed with reductions in height $\Delta h / h_{0}$ of 10 , 30 and $50 \%$.

\section{Spraying of Mist Lubricant}

\subsection{Apparatus of mist lubrication}

To spray the lubricant onto the tool surface, a commercial mist spraying system for metal cutting is used. As shown in Fig. 1, the lubricant supplied from the tank is mixed with compressed air and $1.6 \mathrm{~mL} / \mathrm{h}$ of the lubricant with $0.1 \mathrm{MPa}$ of compressed air is sprayed from the nozzle tips on the tool surface. The nozzle tips are located at $110 \mathrm{~mm}$ from the

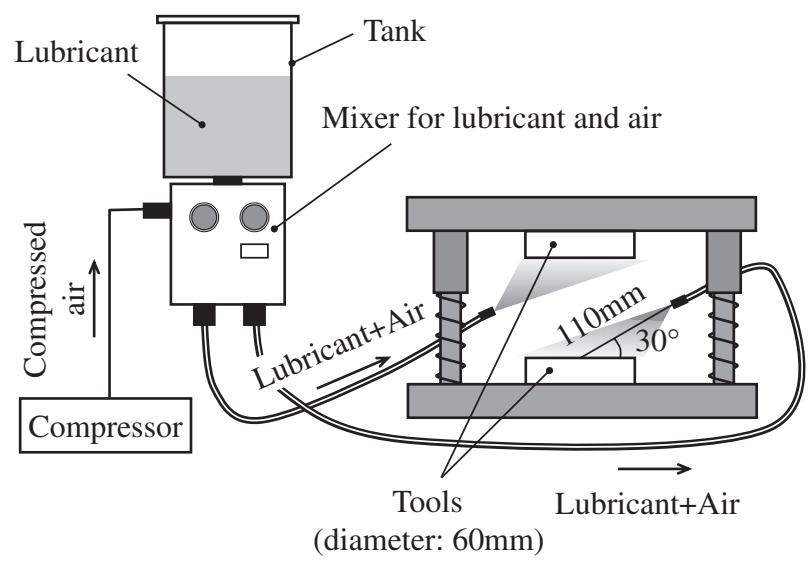

Fig. 1 Apparatus for mist lubricant spraying system. 


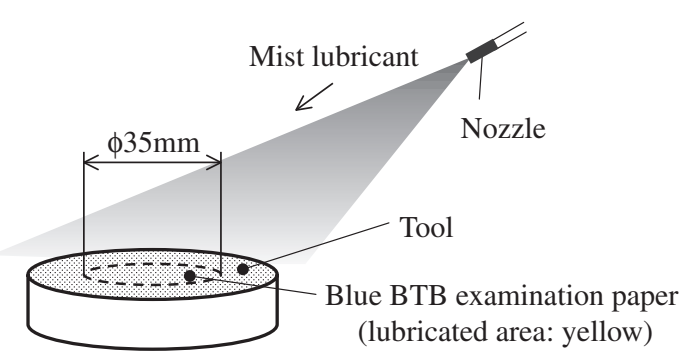

Fig. 2 Measuring method for weight of sprayed lubricant and lubricated area on tool surface.

center of the tool surface at an angle of $30^{\circ}$. Most of the lubricant sprayed from the nozzle tip stays on the whole surface of the tool (diameter of $60 \mathrm{~mm}$ ). A mineral-oil-based lubricant (mineral oil: 70 mass $\%$, alcohol (numbers of carbon: 12 and 13): 30 mass $\%$, kinetic viscosity: $27.7 \mathrm{~mm}^{2} /$ $\mathrm{s}$ (at a temperature of $40^{\circ} \mathrm{C}$ ) and density $\rho=885 \mathrm{~kg} / \mathrm{m}^{3}$ ) is used. While $5-40 \mathrm{~g} / \mathrm{m}^{2}$ of lubricant is used in forging, it is possible to apply approximately $0.1 \mathrm{~g} / \mathrm{m}^{2}$ of a mist of lubricant on the tool surface using this spraying system.

\subsection{Measurements of weight of sprayed lubricant and lubricated area}

In order to determine the amount of sprayed lubricant accurately, the weight of the mist lubricant in a unit area is used as an index. Since the lubricant is not applied uniformly, the sprayed weight of mist lubricant at the central part of the tool surface of a diameter of $35 \mathrm{~mm}$ is measured. In this area of the tool surface, contact with the workpiece takes place during the ring compression test. Because the mist lubricant exists as small dots on the tool surface, the net area covered by the mist lubricant before the ring compression test is also measured.

The weight of mist lubricant applied on the tool surface is investigated from the weight change of a plastic sheet of a diameter of $35 \mathrm{~mm}$ fixed on the tool surface before and after spraying the lubricant. As shown in Fig. 2, the net area covered by the mist lubricant is the colored area of the bromothymol blue (BTB) examination paper fixed on the tool surface. In the wet part of the BTB examination paper with the lubricant, the color changes from blue to red at only the applied area of the mist lubricant, and the net area is determined by the image processing.

In Fig. 3, the relationship between the weight of the sprayed lubricant on the plastic sheet fixed on the tool surface and the spraying duration is shown. Figure 4 shows a photograph of the sprayed lubricant on the BTB examination paper (diameter of BTB examination paper: $35 \mathrm{~mm}$ ). In this study, the ring compression test is performed after spraying the lubricant for $0-75$ seconds. It is considered that the maximum ratio of the lubricated area is approximately $25 \%$, and most of the tool surface is not covered by the lubricant.

\section{Results of Ring Compression Test with Mist Lubri- cation}

The friction coefficient of the aluminium billet lubricated upon mist lubrication is measured using the ring compression

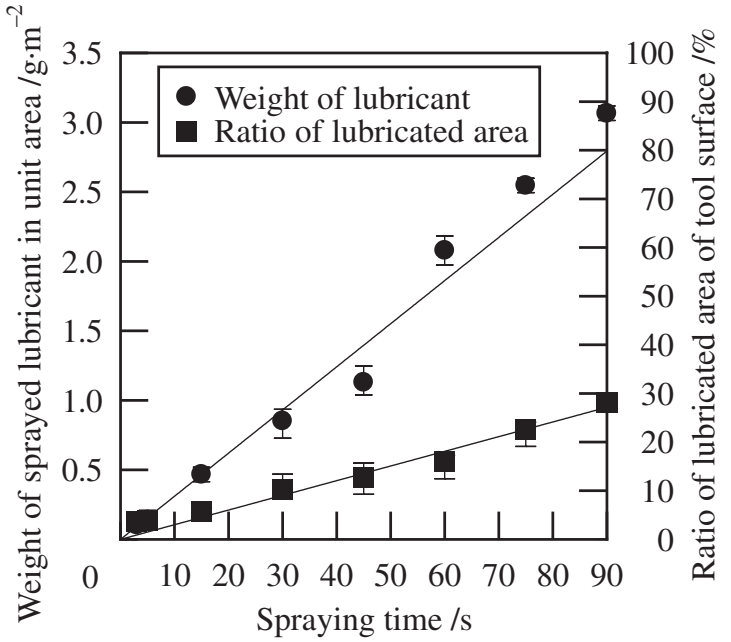

Fig. 3 Relationship between weight of sprayed lubricant on tool surface and spraying time.

test at room temperature and $200^{\circ} \mathrm{C}$. In Fig. 5, the effect of the weight of the sprayed lubricant on the friction of the aluminium billet is shown. Under dry conditions, the coefficient of friction is $\mu=0.14-0.23$ at room temperature or greater than 0.20 at a temperature of $200^{\circ} \mathrm{C}$. On the other hand, when $0.5 \mathrm{~g} / \mathrm{m}^{2}$ of lubricant is sprayed on the $\mathrm{WC}$ tool surface, the coefficient of friction decreases from 0.30 to 0.10 at a temperature of $200^{\circ} \mathrm{C}$. Even when the amount of mist lubricant sprayed is more than $0.5 \mathrm{~g} / \mathrm{m}^{2}$, the coefficient of friction does not become less than 0.08 . This result means that $0.5 \mathrm{~g} / \mathrm{m}^{2}$ is the minimum amount of mist lubricant necessary to maintain a low friction during upsetting of the aluminium billet.

The maximum contacting pressure during upsetting of the aluminium ring is shown in Fig. 6. The maximum contacting pressure is calculated from the maximum load and the maximum contacting area between the tools and the aluminium billet during ring compression. Similarly to the friction coefficient result (Fig. 5), it is possible to reduce the maximum contacting pressure to a half that under dry conditions at the forming temperature of $200^{\circ} \mathrm{C}$ by applying a mist of the lubricant more than $0.5 \mathrm{~g} / \mathrm{m}^{2}$.

From these results, it is considered that approximately $0.5 \mathrm{~g} / \mathrm{m}^{2}$ of the mist lubricant reduces the friction and the load significantly, but more than $0.5 \mathrm{~g} / \mathrm{m}^{2}$ of the mist lubricant does not reduce these further.

\section{Discussions}

\subsection{Maximum and average thickness of sprayed mist lubricant on tool surface}

The maximum thickness of the mist lubricant is calculated under the assumption that the mist lubricant is uniformly distributed in the area covered by lubricant. On the other hand, the average thickness of the mist lubricant is calculated by dividing the amount of the sprayed lubricant by the whole area of the tool surface. Figure 7 shows the relationship between the lubricant thickness and the spraying time. The maximum thickness of the mist lubricant is 3-30 times thicker than the average thickness of the mist lubricant. It is 


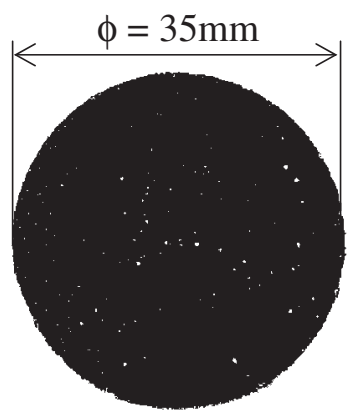

(a) $3 \mathrm{~s}$

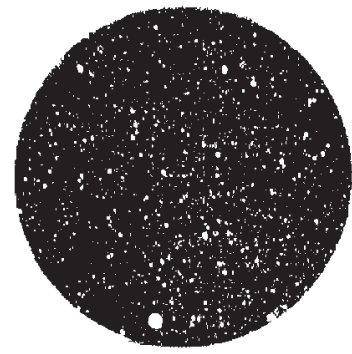

(d) $30 \mathrm{~s}$

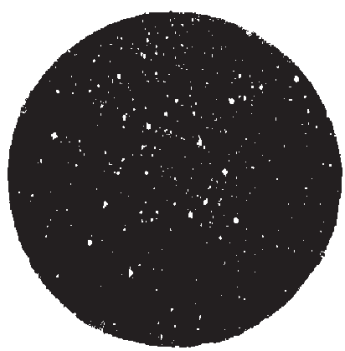

(b) $5 \mathrm{~s}$

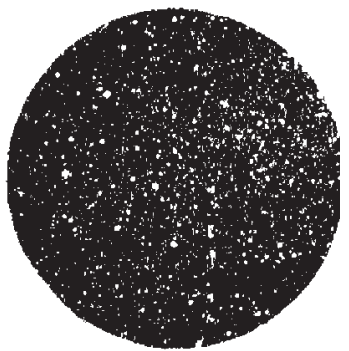

(e) $45 \mathrm{~s}$

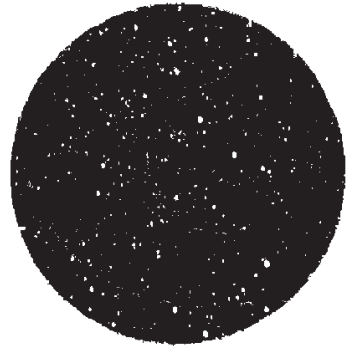

(c) $15 \mathrm{~s}$

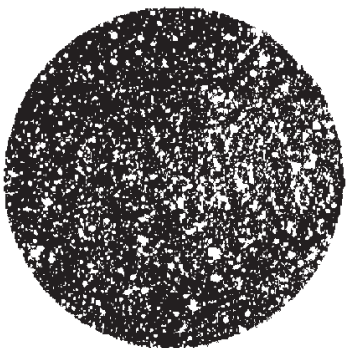

(f) $75 \mathrm{~s}$

Fig. 4 Sprayed lubricant on BTB examination paper fixed on tool surface (diameter of BTB examination paper: $35 \mathrm{~mm}$ ).

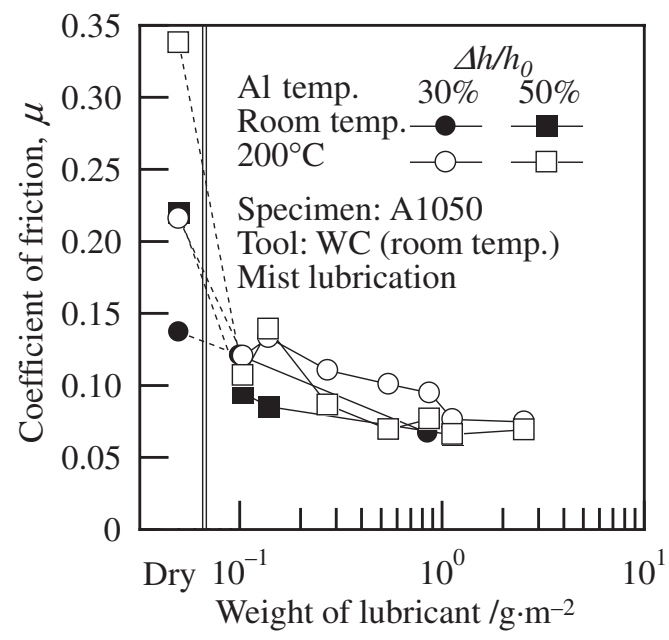

Fig. 5 Effect of weight of sprayed lubricant on coefficient of friction in ring compression test of aluminium billet at room temperature and elevated temperature.

found that a large part of the tool surface is not covered by the lubricant and is under dry conditions at the beginning of the forming with mist lubrication.

When a sufficient amount of the lubricant is applied, the maximum thickness of the lubricant trapped between the tool and the workpiece in compression is calculated by the following equation. ${ }^{13)}$

$$
t_{c}=\sqrt[3]{3 \eta_{0} u R^{2} / P_{0}}
$$

where $\eta_{0}$ is the viscosity of the lubricant $(\mathrm{Pa} \cdot \mathrm{s}), u$ is the speed of compression $(\mathrm{m} / \mathrm{s}), R$ is the radius of the cylindrical workpiece $(\mathrm{m})$ and $P_{0}$ is the flow stress of the workpiece $(\mathrm{Pa})$. In this study, these parameters are $\eta_{0}=24.5 \mathrm{mPa} \cdot \mathrm{S}, u=$

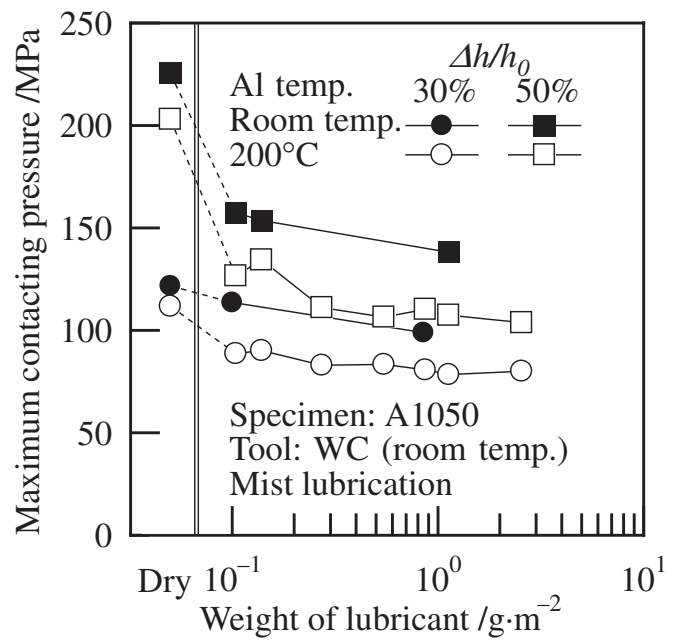

Fig. 6 Effect of weight of sprayed lubricant on maximum contacting pressure when aluminium ring specimen is compressed with WC tools.

$150 \mathrm{~mm} / \mathrm{s}, R=10.5 \mathrm{~mm}$ and $P_{0}=150 \mathrm{MPa}$. The maximum thickness $t_{c}$ which can be trapped is estimated to be $4.3 \mu \mathrm{m}$ using eq. (1). Because the mist lubricant is sprayed on the tool surface for $0-75$ seconds in this study, the average thickness of the mist lubricant is estimated to be $0-2.9 \mu \mathrm{m}$ from Fig. 7. Thus, it is considered that the mist lubricant applied on the tool surface is completely trapped between the tool and the workpiece in ring compression.

\subsection{Measurement of friction in thin-film lubrication}

In mist lubrication, the mist particles stick to the tool surface as dots and a large part of the tool surface is left dry. In order to compare mist lubrication with thin-film lubrication, the friction coefficient of the aluminium billet upon thin- 


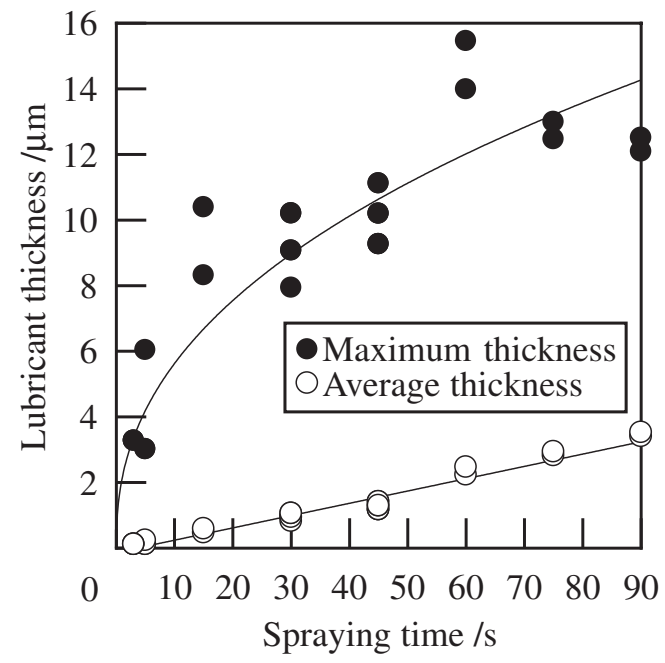

Fig. 7 Maximum and average lubricant thickness estimated from weight of sprayed lubricant on tool and lubricated area of tool.

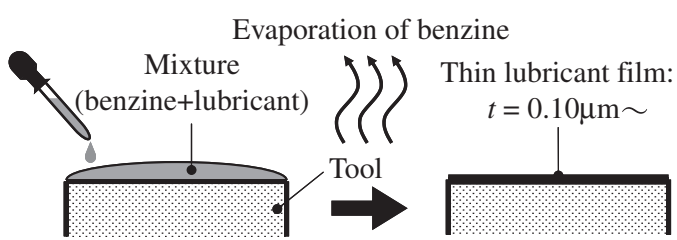

(1) Before application of mixture

(2) After evaporation of benzine

Fig. 8 Method of forming thin lubricant layer on tools.

film lubrication is measured with the ring compression test.

A method for depositing a thin lubricant film on the tools is shown as Fig. 8. To form a thin lubricant film on the tool surface, a known amount of lubricant is mixed with benzene and spread over the tool surface uniformly using a pipet. The benzene evaporates in approximately 20 seconds, and a lubricant film is left after evaporation of the benzene, the film thickness is estimated from the initial volume of the mixed lubricant. With this method, a very thin lubricant film of $0.10-2.0 \mu \mathrm{m}$ can be formed on WC tools at room temperature. In this study, the thickness of the lubricant film is controlled in the range of $t=0.25-2.0 \mu \mathrm{m}$.

Figures 9 and 10 show the effects of the thin-lubricant film on the coefficient of friction and the maximum contacting pressure when the aluminium specimens are compressed at room temperature and $200^{\circ} \mathrm{C}$. The thin lubricant film reduces the coefficient of friction from 0.35 to 0.10 at $200^{\circ} \mathrm{C}$. When the thickness of the lubricant film is greater than $0.50 \mu \mathrm{m}$ (the amount of lubricant applied on the tool surface is greater than $0.45 \mathrm{~g} / \mathrm{m}^{2}$ ), the lubricant gives a low coefficient of friction $\mu=0.10$ and a low contacting pressure similarly to mist lubrication.

The roughness of the compressed aluminium specimen after the ring compression test $\left(\Delta h / h_{0}=50 \%\right)$ is shown in Fig. 11. Under dry conditions, the roughness of the tools is transferred directly to the surfaces of the aluminium specimen during compression, and the surfaces of the aluminium specimens become to have almost the same roughness as the

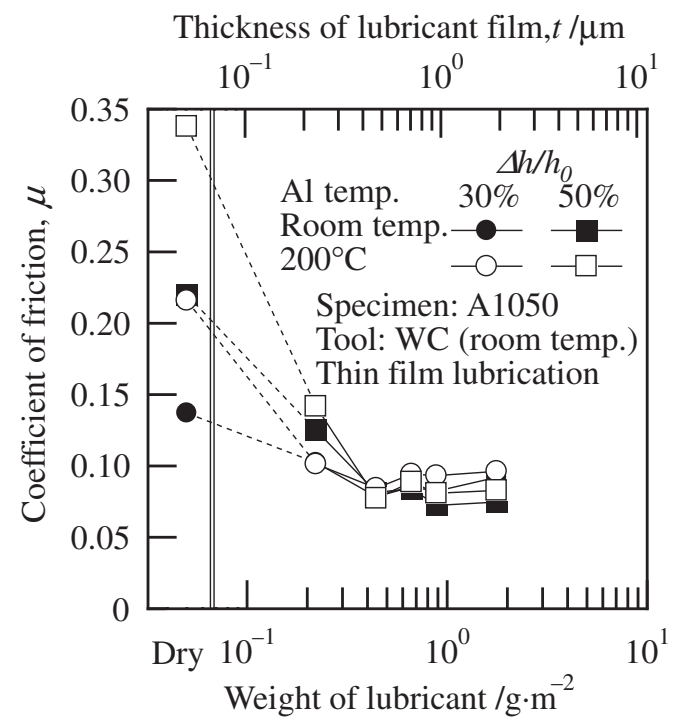

Fig. 9 Measured coefficients of friction for aluminium billet with thin lubricant film.

tool. On the other hand, in both the mist and thin-film lubrications, the roughness of the specimen after compression increases with the amount of applied lubricant, and becomes $R_{a}=0.20-1.8 \mu \mathrm{m}$ which is of the same order as the thickness of the lubricant film.

From these results, it is found that the frictional behaviour of the aluminium billet upon mist lubrication is almost the same as that upon thin-film lubrication. Furthermore, because a film thickness less than $0.50 \mu \mathrm{m}$ is hardly controlled in film lubrication, mist lubrication is a practical method of realizing metal forming with slight lubrication.

\subsection{Lubrication mechanism of mist lubricant during forging}

Figure 12 shows the surface profiles of the aluminium billet after compression with the flat WC tools at room temperature. The thin-film and mist lubricant are applied on the tool surface with an average thickness $t=1.0 \mu \mathrm{m}$ and the ratio of the lubricated area of the tool surface is approximately $10 \%$ in mist lubrication. For all reductions in height, the surface roughness of the compressed aluminium billet under dry conditions is smoother than that the lubricated one. When the aluminium billets are compressed up to $\Delta h / h_{0}=$ $10 \%$ (the maximum contacting pressure is approximately $95 \mathrm{MPa}$ ), the surface roughness of the compressed aluminium billet with mist lubrication is smoother than that with thinfilm lubrication. The mist lubrication gives a coefficient of friction of $\mu=0.10$, and the thin-film lubrication gives $\mu=0.069$. It is considered that the thin-film lubricant is trapped between the tool and the billet uniformly, but the mist lubricant does not spread over the whole contacting part in the early stage of compression.

In the case of $\Delta h / h_{0}=30$ and $50 \%$ (maximum contacting pressures of 110 and $130 \mathrm{MPa}$ respectively), the surface roughness of the compressed aluminium billet upon mist lubrication is rougher than that upon thin-film lubrication, but the surface profiles and the friction coefficients of aluminium are the same in both the mist and thin-film lubrications. It is 


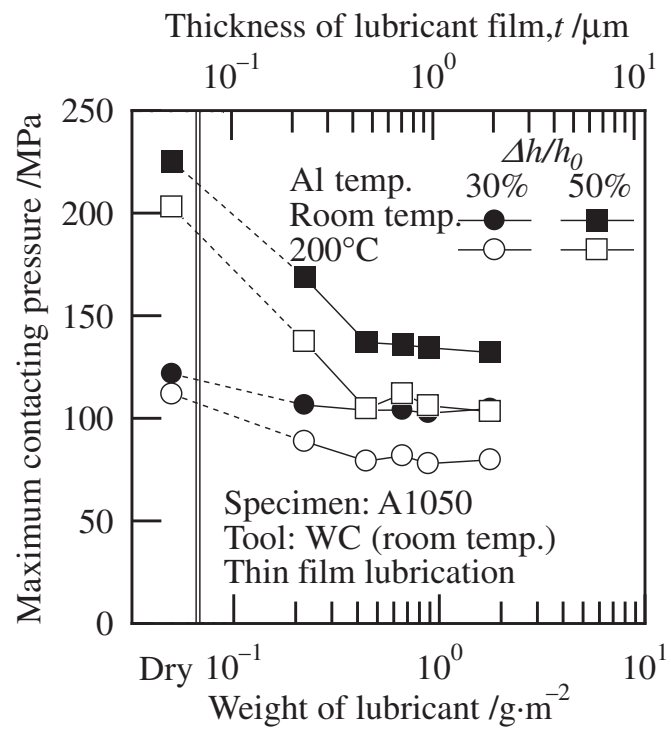

Fig. 10 Maximum contacting pressure for aluminium billet with thin lubricant film in ring compression test.
Thickness of lubricant film, $t / \mu \mathrm{m}$

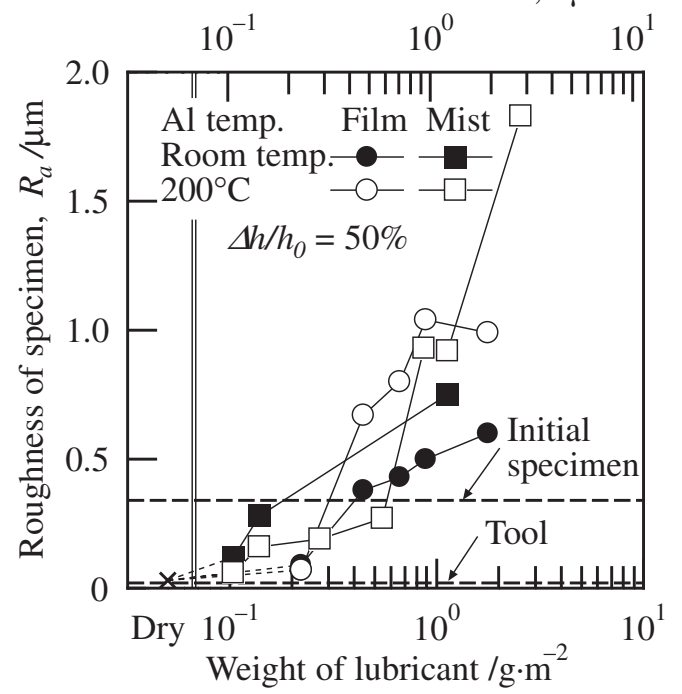

Fig. 11 Effect of thin lubricant on roughness of aluminium specimen after ring compression test.

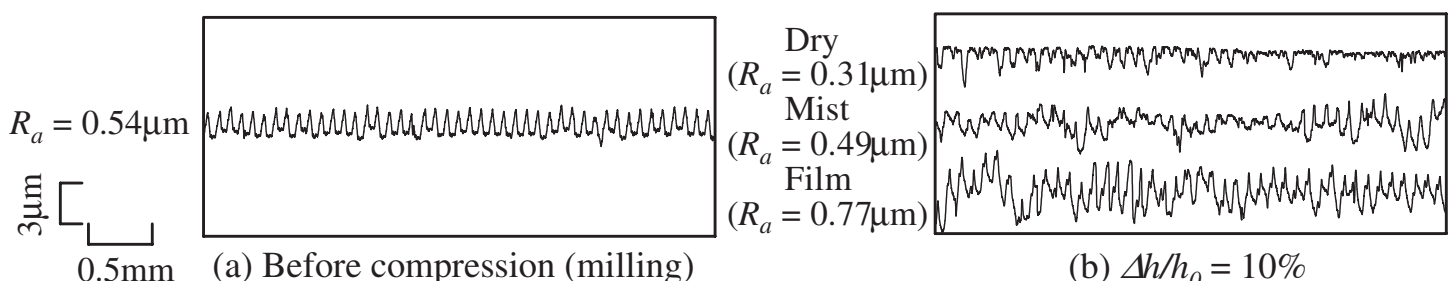

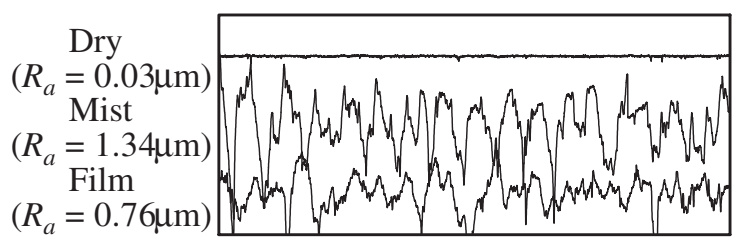

(c) $\Delta h / h_{0}=30 \%$

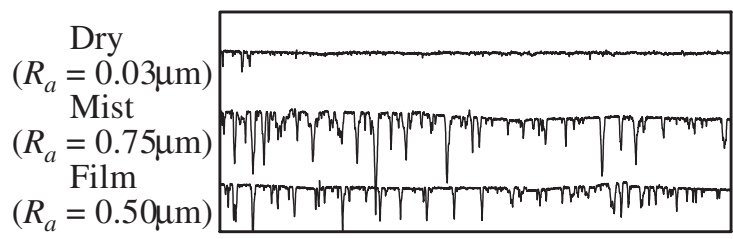

(d) $\Delta h / h_{0}=50 \%$

Fig. 12 Surface profiles of aluminium billet after compression with flat WC tools at room temperature (thickness of lubricant film $t=1.0 \mu \mathrm{m})$.

considered that the mist lubricant spreads from dots to a film over the whole contacting part during upsetting.

\section{Effect of Viscosity of Lubricant on Friction under Semi-dry Conditions}

Figure 13 shows the effect of the kinetic viscosity of the lubricant on the friction coefficient of the aluminium billet upon thin-film lubrication. The film thickness of the lubricant is $t=0.50$ and $1.0 \mu \mathrm{m}$ and the kinetic viscosity of the lubricant is $27.7-25000 \mathrm{~mm}^{2} / \mathrm{s}$ at a temperature of $40^{\circ} \mathrm{C}$. Polybutene (density $\rho=902 \mathrm{~kg} / \mathrm{m}^{3}$ ) has a kinetic viscosity of $8500,25000 \mathrm{~mm}^{2} / \mathrm{s}$. The friction coefficient of the aluminium billet increases by approximately 0.03 when the viscosity increases from $27.7 \mathrm{~mm}^{2} / \mathrm{s}$ to $25000 \mathrm{~mm}^{2} / \mathrm{s}$. To spray the mist lubricant accurately on the tool surface, a lowviscosity lubricant (less than the viscosity of $30 \mathrm{~mm}^{2} / \mathrm{s}$ of the mist spraying system used in this study) must be used, and

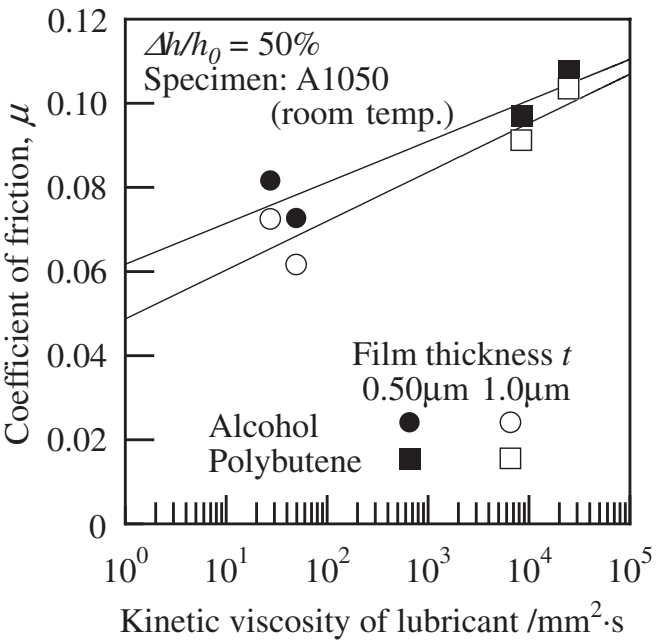

Fig. 13 Effect of kinetic viscosity of lubricant on friction coefficient of aluminium billet under thin lubricant condition. 
semi-dry metal forming sprayed with a small amount of lowviscosity lubricant is considered to be practically usable.

\section{Conclusions}

In this study, a very small amount of mist lubricant is sprayed on a tool surface, and the frictional behaviour and mechanism of mist lubrication is investigated during upsetting of an aluminium alloy. The following conclusions are obtained.

(1) In comparison with dry conditions, $0.5 \mathrm{~g} / \mathrm{m}^{2}$ of lubricant reduces the coefficient of friction and the forming pressure to less than $50 \%$ during upsetting of an aluminium alloy.

(2) Before forming, a large part of the tool surface is not lubricated in semi-dry metal forming with mist lubrication, but mist lubricant is extended to the whole tool surface during compression, and the friction is kept to be low.

(3) The lower the viscosity of a lubricant is, the lower the friction is during forming under slight lubrication, and it is difficult to spray a lubricant of high viscosity. The mist spraying system for metal cutting is effective in realizing semi-dry metal forming.

\section{Acknowledgements}

The authors wish to acknowledge the assistance of Mr. T.
Onishi of Osaka University and would like to thank DIJET Industrial Co., Ltd. and KYOEI OIL Co., Ltd. for providing the cemented carbide dies and lubricants used in this research. The authors would also like to express their appreciation to the Japan Society for the Promotion of Science.

\section{REFERENCES}

1) S. Kataoka: Journal of the Japan Society for Technology of Plasticity 43-492 (2002) 3-10.

2) Y. Suzuki: Journal of Japanese Society of Tribologists 47-7 (2002) 526-532.

3) S. Ikawa, M. Iwatsubo and K. Miyazaki: Mech. Eng. 47-5(1999) 1822.

4) T. Kumagai: Journal of the Japan Society for Technology of Plasticity 38-435 (1997) 304-308.

5) N. Koga and R. Paisarn: Journal of the Japan Society for Technology of Plasticity 42-481 (2001) 145-149.

6) K. Osakada and R. Matsumoto: Ann. CIRP 49-1 (2000) 161-164.

7) W. Bartz: Tribol. Int. 31/1-3 (1998) 35-47.

8) F. Klocke and G. Eisenblätter: Ann. CIRP 46-2 (1997) 519-526.

9) F. Klocke and T. Krieg: Ann. CIRP 48-2 (1999) 515-525.

10) A. Machado and J. Wallbank: Wear 210 (1997) 76-82.

11) D. Hafenbraedl and S. Malkin: Trans. NAMRI/SME 28 (2000) 149154.

12) A. T. Male and M. G. Cockcroft: J. Inst. Metals 93 (1964-1965) 38-46.

13) M. Oyane and K. Osakada: Transactions of the Japan Society of Mechanical Engineers (Part III) 34-261 (1968) 1001-1008. 